\title{
ROCK ART RECORDING IN KHATM AL MELAHA (UNITED ARAB EMIRATES): MULTIRANGE DATA SCANNING AND WEB MAPPING TECHNOLOGIES
}

\author{
Jorge Angás ${ }^{1 *}$, Sabah Abboud Jasim ${ }^{2}$, Manuel Bea ${ }^{3}$, Mercedes Farjas ${ }^{1}$, Paula Uribe ${ }^{4}$, Paloma Lanau ${ }^{3}$, Xosefina Otero ${ }^{1}$ \\ ${ }^{1}$ Universidad Politécnica de Madrid, Spain-j.angas@usal.es,m.farjas@upm.es, artabria@gmail.com \\ ${ }^{2}$ Sharjah Archaeology Authority, United Arab Emirates - m.farjas@upm.es \\ ${ }^{3}$ Universidad de Zaragoza, Spain - manubea@unizar.es; palomalanau@gmail.com \\ ${ }^{4}$ Universidad de Salamanca, Spain - uribe@usal.es
}

\section{Commission II, WG II/8}

KEY WORDS: Petroglyphs, Iron Age, open-air rock art, 3D models, web mapping, open-source libraries, aerial and terrestrial photogrammetry

\begin{abstract}
:
The application of geometric recording data and representation of open-air rock art is intrinsically so heterogeneous that new online web platforms are required for a more efficient analysis to link all the geo-referenced information and facilitate its scientific study. From 2015 to 2018, three geometric documentation campaigns led by the Departamento de Ingeniería Topográfica y Cartografía of the Universidad Politécnica de Madrid (Spain) were completed in the area of Khatm al Melaha (Emirate of Sharjah, United Arab Emirates) along the Gulf of Oman.

More than 370 rock art engraved motifs were documented in this area close to the southwest border with the Sultanate of Oman. All those figures were picked in 149 stone blocks with different dimensions and morphologies, distributed along the slope of an isolated 58-meter-high elevation.

The aim of this project was to establish a protocol for the recording, analysis, preservation and prevention of this set of open-air rock art engravings with the following actions: developing an aerial and terrestrial recording data documentation, creating and developing a web platform called threeDcloud for visualizing three-dimensional models and web mapping, and integrating a data base by means of different JavaScript open-source libraries.
\end{abstract}

\section{INTRODUCTION}

In this paper we propose a primary methodology procedure that allows integrating into web access of data recorded from the archaeological area of Khatm al Melaha (Emirate of Sharjah, United Arab Emirates), combining different geomatic techniques at different scales from a broad yet technical perspective. In order to improve scientific analysis, the documenting process should always consider every aspect of recording as well as preventive control, conservation and interpretation. Along these lines, some open-access, web-based 2D and 3D JavaScript libraries have been created to unify, simplify and analyse their different uses through a web platform called threeDcloud.

The use of new technologies for recording and identifying openair rock art in nature is so diverse and the techniques applied are often so complex that they hinder interdisciplinary understanding, failing to provide a standardised methodology. New development techniques are hence needed. Procedures should be standardised to provide scientific analysis, as well as dissemination and understanding of the generated data and its possibilities.

Three geometric surveys were carried out between 2015 and 2018 in the archaeological area of Khatm al Melaha (Emirate of Sharjah, United Arab Emirates) along the Gulf of Oman, led by the Departamento de Ingeniería Topográfica y Cartografia, Universidad Politécnica de Madrid (Spain). More than 370 rock art engravings were documented in this area close to the southwestern border with the Sultanate of Oman (Figure 1).

The engravings were carved on 149 stone blocks of different dimensions and morphologies spread along a 58-meter high isolated slope (Figure 2). Some of those decorated boulders are in secondary condition, having rolled down the hill (natural degradation processes) or having been used for some of the modern human structures documented in the area (Figure 1. A). Despite the high concentration of rock art panels, associated archaeological finds were scarce: only two small undecorated handmade pottery fragments, a couple of flint flakes, and a hand mill fragment were found in an examination of the surface area. In order to understand this rock art concentration from a visual perspective, in its location it's easy to see the N-S communication route parallel to the Gulf of Oman, as well as the E-W route to the interior through the Wadi al-Hilu, currently connected by the Sharjah-Kalba highway (Jasim et al., 2016). Apart from those artefacts, a large shell midden was found at the foot of the hill facing East, and some circular structures (in varying conditions) mainly along the Eastern side of the slope but also at the top of the elevation and on the western side. Even though they haven't yet been defined as funeral graves, some other nearby rock art areas have, as it is the case of Fujairah (Ziolkowski, 1998, 2007; Ziolkowski and Hassan, 2000).

Despite being in its preliminary phase, the project has so far seen the following achievements:

1) The creation of a wide catalogue of documentation with strong possibilities of dissemination, such as a $2 \mathrm{D}$ and $3 \mathrm{D}$ online repository data.

2) The integration into web access of interrelated models at different scales.

\footnotetext{
* Corresponding author
} 
3) The integration of geomatic techniques for preventive control, conservation and interpretation of open-air rock art.
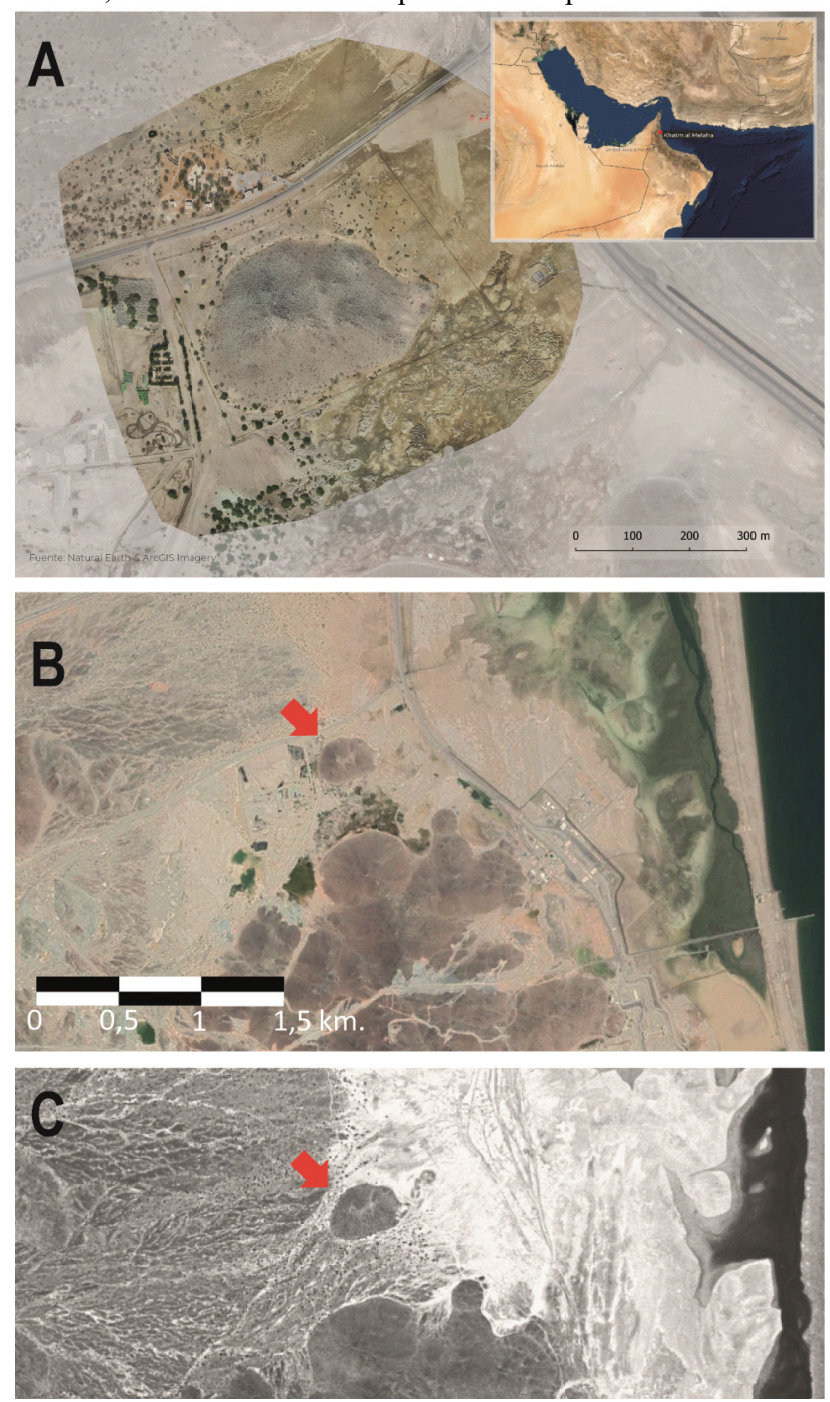

Figure 1. A) Location of Khatm Al Melaha on the Southeast border with the Sultanate of Oman (Natural Earth \& ArcGIS Imagery) (Emirate of Sharjah, UAE). B) Current satellite image on Google Satellite view. C) Contrast of the coastline and transformation of the archaeological landscape with the CORONA Satellite image DS1116-2202DA031 on May 2, 1972 (USGS, EROS).

\section{GOALS AND METHODOLOGY}

The main goal of this project is to establish a protocol for recording and preserving this group of engravings with the following actions:

A. Develop a multi-scalar documentation (Figure 3) in order to understand each rock art panel, the relationship among them as well as their logical geospatial location within the archaeological context. One of the three-dimensional digitalisation goals is to optimise time recording data and improve the results of both metric and graphic data. Credible data for testing and analysing is therefore obtained, while there is also a significant increase in the data obtained when recording. In order to develop the archaeological documentation for this site, the following geomatic techniques have been used in all three completed campaigns:

- Photogrammetric tablet (2015). Some of the rock engraving panels were documented with a photogrammetric tablet EyesMap (Otero et al., 2016, 2017, Ovejero, 2016) so as to obtain different orthophotos and 3D models for the first analyses.

- Aerial photogrammetry with a fixed-wing drone (2016). We have used an eBee drone by senseFly, aiming to generate an orthophoto with a resolution (GSD) of 2-centimetrepixel of the entire archaeological site, approximately 70 hectares. This technique allows of a better spatial resolution to locate the different rock art panels.

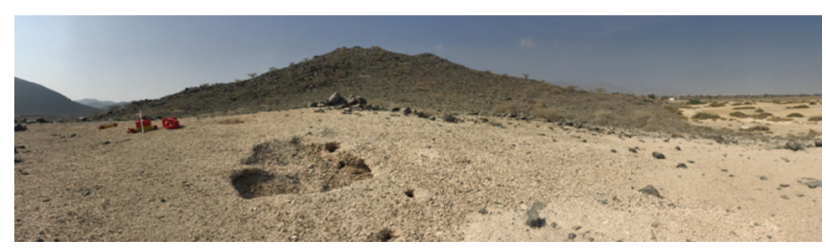

Figure 2. Current panoramic view of the archaeological site Khatm al Melaha from the coast.

- Close range photogrammetry techniques (2018). In 2018, an intensive archaeological survey was conducted in the entire archaeological site in order to document each rock engraving with close range photogrammetric techniques and a database. The results were the finding of 149 block stones with more than 370 rock art engravings.

- Digital treatment of the images and digital tracing of the motifs by using orthophotos. This sort of images is not just an isolated tracing, giving us information in many ways (morphological, preservation, support context). Decorrelation stretch by DStretch and radiance scaling by Meshlab (CarreroPazos et al., 2017) have been tested on the texture of the 3D model.

- GNSS RTK - PPK $(2015,2016,2018)$. All surveys were georeferenced with a GNSS RTK Leica GRX1230 by means of Post-Processed Kinematic techniques (PPK).

B. To launch a database that is interrelated and integrated into web pages in order to obtain a more detailed analysis of rock engravings. We have used the epicollect 5 mobile \& web application for data collection in field activities (2018).

C. Create and develop a web platform called threeDcloud for visualising three-dimensional models and high-resolution images, allowing real-time interaction of the information. This web platform is based on Potree, a free open-source WebGL to manage large point clouds (Schütz, 2016), an open-source JavaScript library to adapt the orthophoto generated into a web mapping by means of Leaflet, a JavaScript 3D library, and a decorrelation view to analyse the 3D mesh of each rock art panel (Three.js, DStretch). 

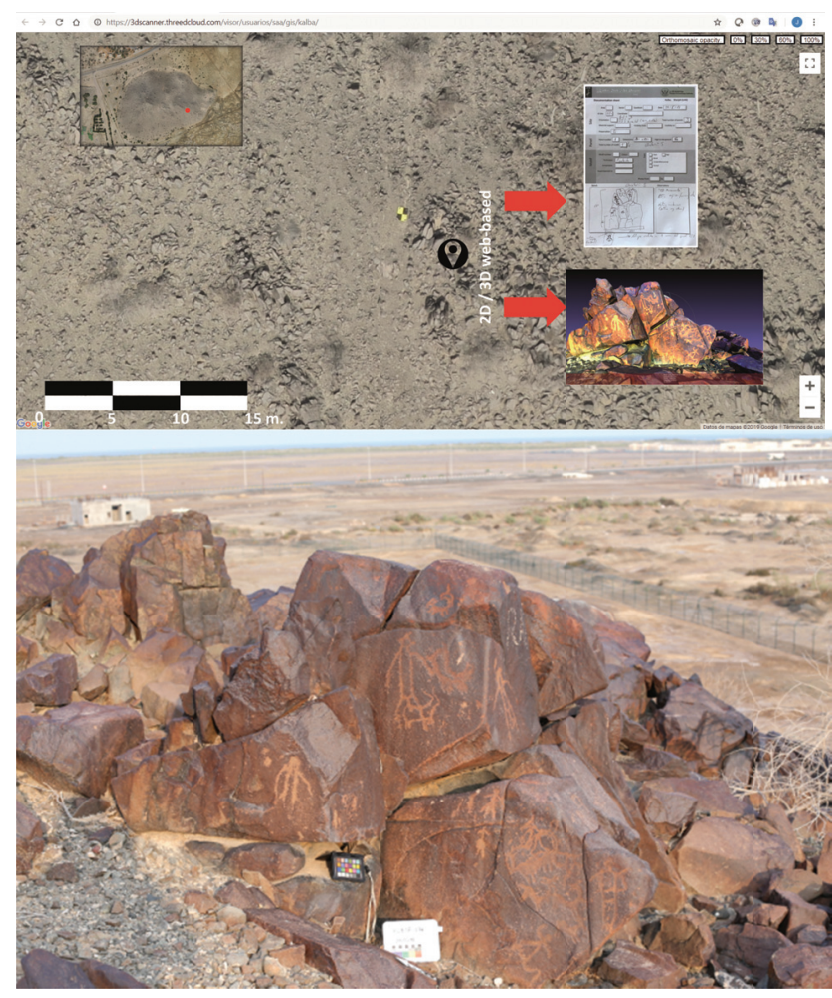

Figure 3. Example of a database (above) through a web mapping linked to the various data (survey form field sketches, aerial and terrestrial pictures, 3D mesh, large point cloud, 360 immersive view, de-correlation view, etc); (below) survey field

texture documentation with a standardized colour chart.

\section{DATA ACQUISITION}

\subsection{Eyes map tablet}

In November 2015, a first documenting campaign of 22 selected open-air rock arts from the archaeological site was completed with Eyesmap (Figure 4) system (ecapture). The aim was to create a preliminary documentation of both ortophotos and 3D models (Ovejero, 2016).
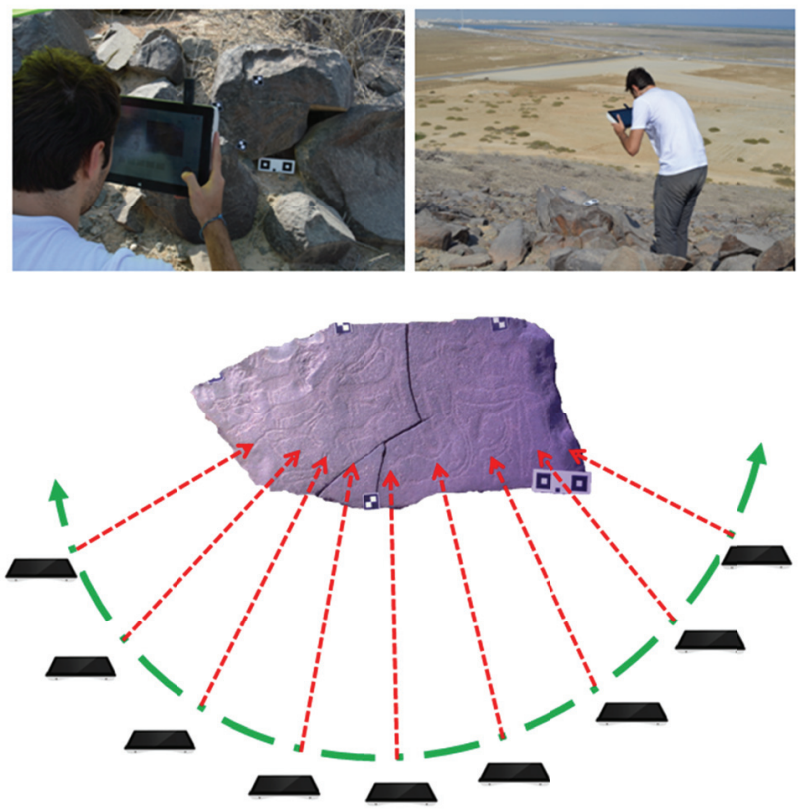

Figure 4. In-site work methodology with an Eyesmap tablet and StereoTargets (Ovejero, 2016).

The system is based on the distribution of a base line between two cameras that require several StereoTarget markers to capture the surface at a 1.5 -metre distance. At this working distance, the highest deviation from the model was of 2.2 millimetres. It also has gyroscope, accelerometer and compass, a GNSS sensor L1 mono-frequency for GPS, GLONASS, GALILEO, QZZS, COMPASS and SBAS L1. Due to environmental conditions the radiometric adjustment rendered from the images was nonetheless not the adequate.

\subsection{Aerial photogrammetry}

In 2016, a documenting campaign was completed with a fixedwing eBee drone (from senseFly model) with visible spectral sensor. The adaptability to DSM of this drone allowed generating a 3.65-centimetre/pixel GSD of the whole archaeological site (72 ha.) at a 120-metre height. The sensor used was a G9X Canon camera with a 20-mp resolution. The focus was to generate a 3D-model and a high-resolution orthophoto of the working area (Figure 5). Several GCP control points we distributed all over the site at different heights in order to monitor the final model. The absolute camera position (mean uncertainty) was $0.024(\mathrm{X})$ 0.025(Y) $0.039(\mathrm{Z})$.

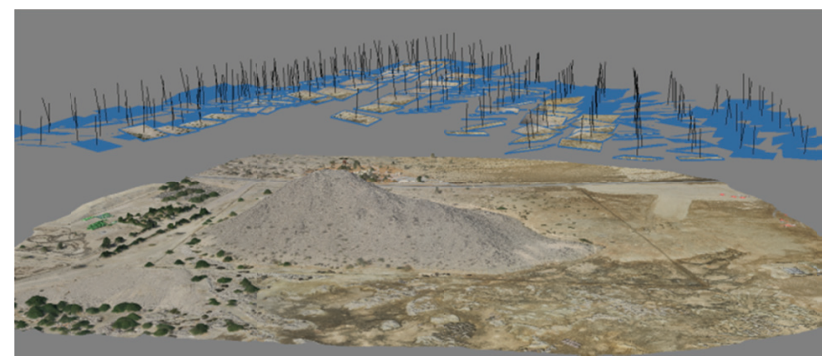

Figure 5. Dense point cloud obtained by aerial photogrammetry using Agisoft Metashape software.

\subsection{Terrestrial photogrammetry}

In 2018, an intensive compiling campaign of each of the rock art engravings was finally completed with terrestrial photogrammetry techniques using a $6 \mathrm{D}$ Cannon with a 50milimitre lens. For each of the 159 models, a calibrated colour chart was used to get a radiometric adjustment of the images. However, since some of the resulting images and models were going to be used for digital tracing, these were taken at night with an annular flash to obtain homogenised light conditions. A lateral slave flash was also used to reproduce a steady volume in the model that could later be used for a better stylistic classification (Figure 6).

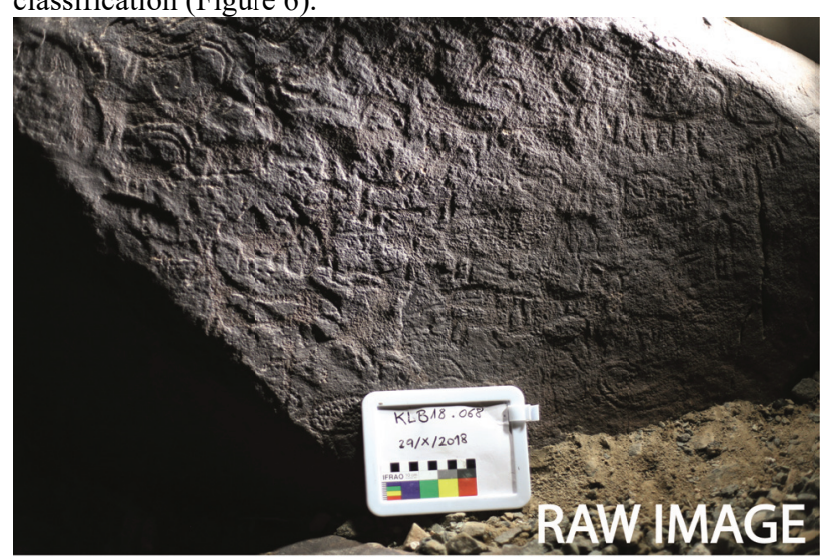



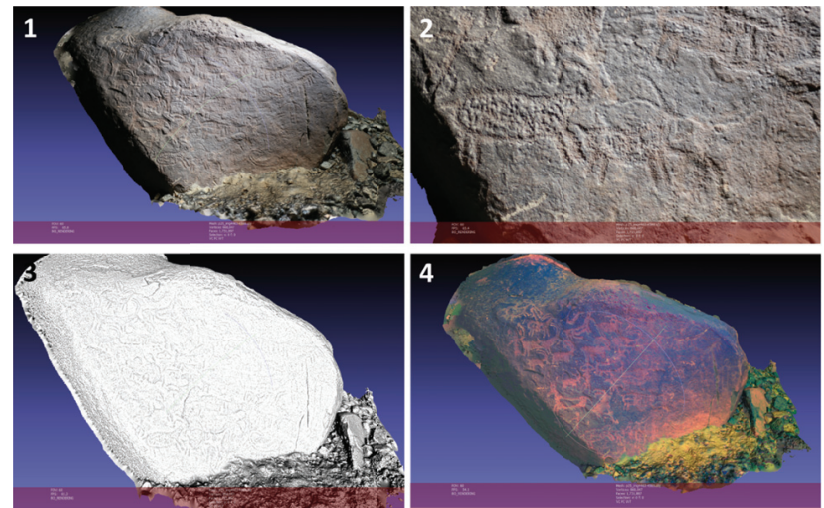

Figure 6. Raw image acquired with indirect light during the night (panel 68) (above). Figure 6.1-6.2 High resolution 3D model and detail. Figure 6.3 3D model with radiance scaling processed with Meshlab. Figure 6.4 Final 3D model textured with decorrelation stretch in colorspace YBK (DStretch).

\section{DIGITAL TRACING}

On rock-art studies it is "imperative the faithful restitution of the artworks and their supports" (Sauvet, 2011: 14). The need to overcome the concept of "tracing", as an image isolated from its support, has already been referred in many other studies. Tracing has always been an extraordinary tool for different reasons (Lorblanchet, 1993). On the one hand, it helps clarifying some unsolved issues; on the other hand it makes it possible for us to learn about the real nature of what it was represented. By providing a clearer image of the tracing, the preserved motifs can be better understood, which in turn helps us identify patterns of superimpositions between figures. Consequently, once we have analysed in detail the decorated panels during the elaboration process, we will be able to share our study with researchers and with a general audience.

This idea was already held in the first publications about rockart sites. See, for example, those drawings from different parts of the World (Bahn, 1997) or the very first general representation of a Palaeolithic cave art, the "polychrome ceiling" of Altamira carried out by Paul Ratier (Sanz de Sautuola, 1880).

Regarding analogical tracing, this can be either direct or indirect (the last one uses photographs or projected slides). It would be expected from analogical tracing to be an impartial process, considering that tracing directly from the model would give little margin to personal interpretations, but this is far from being the case. It is possible to appreciate differences between tracings of the same motif, even when using digital techniques (Le Quellec et al., 2015). In certain cases this could be explained by perspective changes or distortions generated when making a neat copy (going from a $3 \mathrm{D}$ reality to a $2 \mathrm{D}$ plate), because of the method used (direct tracing followed by laboratory work without any verification step), due to a different visibility of the motif throughout the years, or because of the different skills of the tracing creator.

We have applied a digital tracing method by using orthophotos and a digital image treatment by DStretch (Figure 10). Despite not being a methodological innovation in itself, it can be defined as a state of art-technologies, taking into account that many research teams are using similar standards (RogerioCandelera et al., 2011; Le Quellec et al., 2013; Domingo, 2014; Bea and Angás, 2017), even with regard to engravings (Defrasne, 2014; Robin, 2015). What can be considered truly innovative is applying such methodology to this area, because it goes beyond traditional documentation procedures and it renders highly accurate results. This, together with the rest of the geometric recording data (that is, digitally processed images and digital tracing) yields a coherent workflow that combines the results of each documenting process.

Moreover, our goal is to present not just an image of an isolated tracing, but to highlight the image of a tracing with its original context (Figure 7). Such treatment of the tracing gives essential information for global studies of rock panels: its connection with the volumetric component of the shelter (which determines the reading of the represented setting), the definition of preservation elements, both natural (cracks, fissures, flacking, etc) or anthropic; or even those related with widespread.
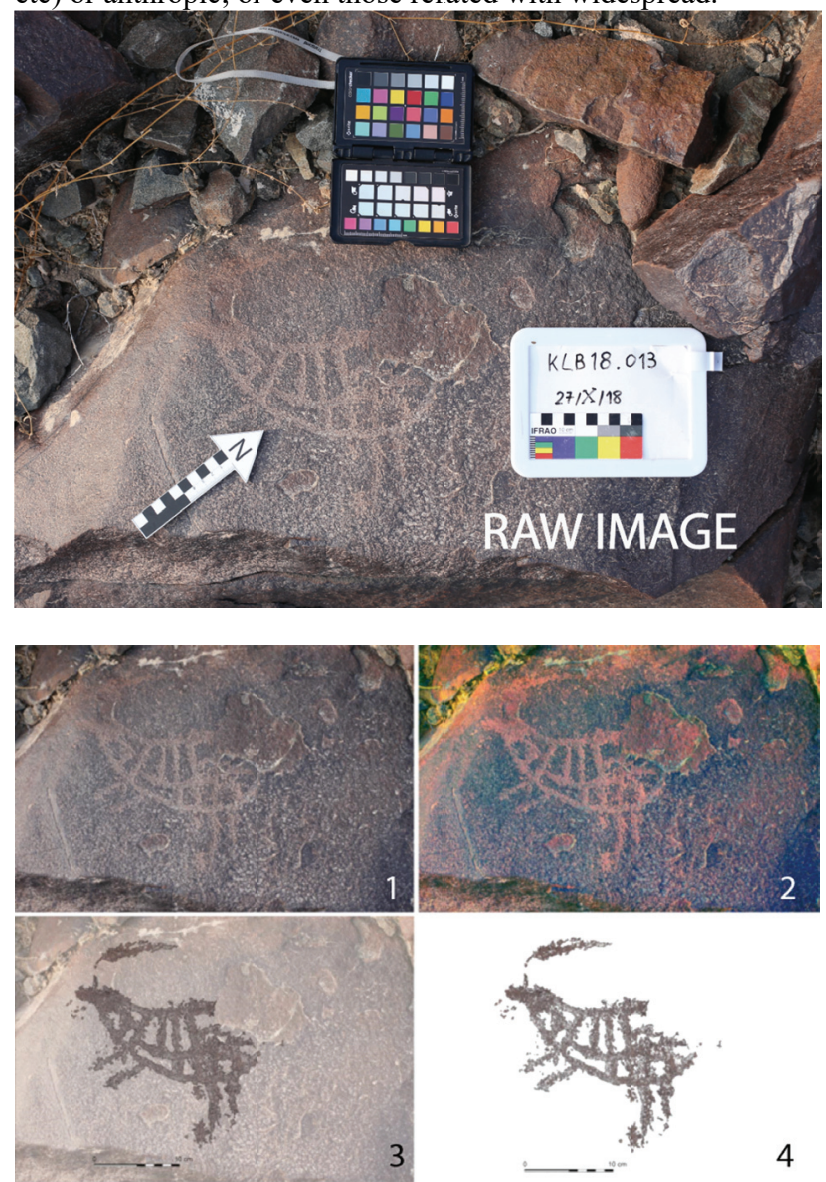

4
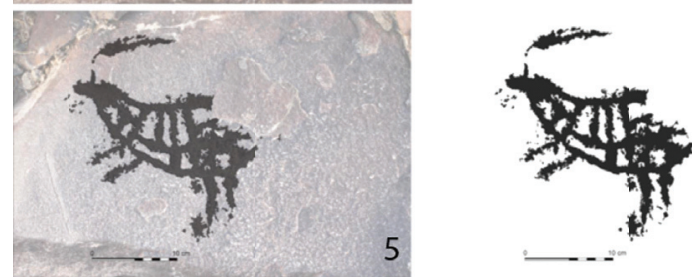

6

Figure 7. There are different phases on digital tracing of one of the engraved motifs. ID-13 represents an ibex with its body partially filled. Some fissures and cracks have affected the preservation of the figure, especially on its hinds and the beginning of the horns.

\subsection{Methodology}

The tracing generation process is simple and could be described as an indirect system. From the original images, an orthophoto and a 3D texture are created from the model (Figure 7.1). The image is subsequently processed with a variety of DStretch filters that de-correlate colour (Figure 7.2), creating falsely coloured images that emphasise certain spectrums. This step allows clearer observation of the images. All images created 
were edited with Photoshop, using several tools such as Magic Wand, Lace Tool and Colour Range Command, depending on the specific needs of each area of the image. Those pixels that do not correspond with the engraved area are eliminated, and the image is isolated in a particular layer to show the rock art engraving separated from its physical support.

Additionally, a copy of the original image is created with lowered opacity in a different layer. The tracing previously created is superimposed onto this image, thus highlighting the engraving while presenting visual information about the physical support in which it was created (Figures 7.3 and 7.5). There are multiple possibilities of quickly modifying the tracing once obtained, being a versatile method that allows for a variety of results depending on the needs (Figures 7.4 and 7.5). Alternatively, other automatized systems such as Meshlab and DStretch were tested on the 3D model texture highlighting the latter (Figure 6).

\section{ABOUT OPEN-AIR ROCK ART: CONNECTIONS BETWEEN ROCK ART AND LANDSCAPE TOPOGRAPHY}

Even though there are some studies relating to rock-art in Arabia (Anati, 1968a, 1968b, 1968c, 1972, 1974; Bednarik and Khan, 2005, 2017; Khan, 2007, 2013; Newton and Zarins, 2000), those located in the United Arab Emirates are less numerous (Ziolkowski, 1998, 2007; Ziolkowski and Hassan, 2000). Despite being in its preliminary stage, this project has an inductive approach that goes from the particular to the general, classifying the rock-art motifs according to a distinctive classification in order to compare it to those from other areas. Therefore, in this initial phase of the project, we have tried to classify the documented study at Khatm al Melaha according to four different parameters: style, technique, topic and colour of the patina, all of them concerning the particularities of the region.

\subsection{Style}

Ascribing a specific artistic style to one culture or historical period seems a rather confusing task. In the debate about the appropriateness of the term "art" for graphic prehistoric representations, the discussion about the concept "style" has some interest.

The idea of style appears somewhat confusing for archaeologists and pre-historians, being "one of the most difficult concepts in the lexicon of art and one of the chief areas of debate in Aesthetics and Art History" (Turner, 1996). Nevertheless, we consider that this term is essential for interpretation as well as for many other fields, such as art history, social studies, etc. Understanding the term as a coherent system of qualities in a certain period, it is also worth highlighting that, for prehistoric rock-art, the term should refer to a wider social group and not to an individual personality.

As we see it, rock-art studies should look into a way of examining the morphological variations of representations to see what type of results about prehistoric societies would a stylistic analysis render. We should inquire what type of formal variables constitute a specific style and try to define the status of the cultural, social and material processes that circumscribe it and materialize it as a cultural characteristic (Roe, 1995: 27).

The challenge is to set those goals that let us single out groups of attributes that can be used to identify certain processes from the past (Carr and Neitzel, 1995). We should understand style not only as a means of doing something but rather as the representation of an idea, since the term surpasses its technical specifications.
Since the end of 20th century some debates have taken place about the idea of style in archaeology, its main line being the discussion about the following questions: how should conceptual style be differentiated? How should function and technology be distinguished in operational contexts? Which factors determine a style? How important is the context in determining a style? What characteristics of a given style are more or less important when reconstructing processes from the past as well as ancient conditions and social units? (Carr and Neitzel, 1995: 6).

To our view, the main line of the debate should focus in establishing those attributes that better differentiate a group of given representations so as to recognize those elements, qualities, proprieties and particularities that delimit a "style". A number of questions then arouse. Would it be possible to isolate a given number of attributes and compare them, in order to interpret their ideological meaning through the contextual associations in the archaeological language? Do the structural aspects of a style always indicate a specific ethnic or cultural group, or can those aspects only reflect a wide range of social groups?

By delimiting stylistic spans in our field we will realise the existence of ethnic regions that have their own characteristics in different levels (the form of the representations, the connection among them, the artistic topic, the archaeological and cultural context, dates, etc.). We hope that the understanding of these regions will help contribute to the general context of rock-art in the Arabic Peninsula, its origin and evolution with consistency in both time and space.

From more traditional views - mostly historicist - the term "style" has been defined in material and contextual terms that are obviously more appropriate for historicist epistemology. Once those parameters were overcome, and perhaps as a reaction to subsequent postulates such as those of the New Archaeology, at the end of the 20th century more modern views appeared. These views understood the debate about the terminology from a rather theoretical perspective, by which styles are seen as an active expression directed to obtaining meaning as much as cultures and social groups are, too. They vary depending on both the context and the historical moment, and all of them highlight certain restrictions that determine each style as a process, whether this is material, economical, social, ecological... (Conkey, Soffer, 1997; Hodder, 1990). This line has been followed by other researchers who understand "style" as an intentional, structured system of selecting certain dimensions of form, process or principle, function, significance, and affect from among known, alternative possibilities to create pleasing variability within a behavioral-artifactual corpus (Roe, 1995: 31).

Indeed, "art is a very difficult word to use successfully" and "the use of art as a descriptive term in relation to petroglyphs, engravings, carvings, etc. is fraught with confusion and subjectivity" (Ziolkowski, 1998: 23). It is for this reason that we use the term "style" with caution even though we believe it should not be forgotten (Clegg, 1993: 102).

Along these lines, considering our observations in our small area of study we have established four different styles, two of which also have specific characteristics that classify in two substyles. According to the morphological characteristics of the engravings, these would be classified as follows:

1. Schematic; 2.1. Synthetic, 2.1. Synthetic hypertrophied; 3.1. Stylised, 3.2. Stylised hypertrophied; 4. Abstract or Symbolic.

This project aims to establish connections between the stylistic phases mentioned and those that have been noted in former studies with a time-cultural value: Islamic, literate, herding and hunting, early hunters (Anati, 1968a, 1968b, 1968c, 1972, 
1974). Given the preliminary state of this analysis, we can only note some suggestions, since we must wait to obtain results from the whole study (style, superimpositions, patinas, themes...) to establish sequences that are supposedly valid.

In any case, the purpose of this first part of the project is to identify and develop a data integration process from the different documenting systems applied. Consequently, this article aims to estimate how to generate a $2 \mathrm{D}$ and $3 \mathrm{D}$ repository that allows research about common stylistic patterns of the engravings, statistics of location and detailed study of each engraving through a web page. It also aims to find the most appropriate method to integrate interrelated models at different scales through the threeDcloud platform without the need of additional software or plugins and, ultimately, the find the combination of all these geomatic techniques that let us progress in preventive control, preservation and the interpreting of rock-art.

\section{RESULTS}

In order to put the technology into full effect, we need to create methods that can be easily spread through 2D and 3D databases in web settings. This kind of data allows for instant viewing and analysis, since it offers valid graphic and metric data from three-dimensional models. User-level interactive databases stored in JavaScript files in browsers (which integrate WebGL) favour free dissemination, since they provide more comprehensive aspects, both technical and scientific.

The libraries used for each of the functions of this web platform are the following:

- Programming language used: PHP / Javascript / HTML

- Database: MySQL

- Operating System, OS (Windows, Linux, etc).

- Apache server

- JavaScript libraries used for the different viewers (Point Cloud, VR360, GIS, etc):

- Point Cloud: three.js, jquery, laszip, Plas.io, OpenLayers3, proj4js, tween, il8next

- VR360: Krpano Panorama Viewer

- GIS: Leaflet, qgis2web, OpenStreetMap

- Mesh: three.js, MA3D, DStretch

- RoadView: krpano, google maps

A general 3D point cloud of the hill, as well as digital models for each engraved block (Figure 8). This is meant to visualize and render large point clouds based on WebGL, a standard for rendering $3 \mathrm{D}$ graphics from any browser that supports it. It is not only used as a viewer, but also has certain tools for processing and using point cloud, such as profiling, area, volume, distance and height measurements, elevations, classification of point clouds and layers division.

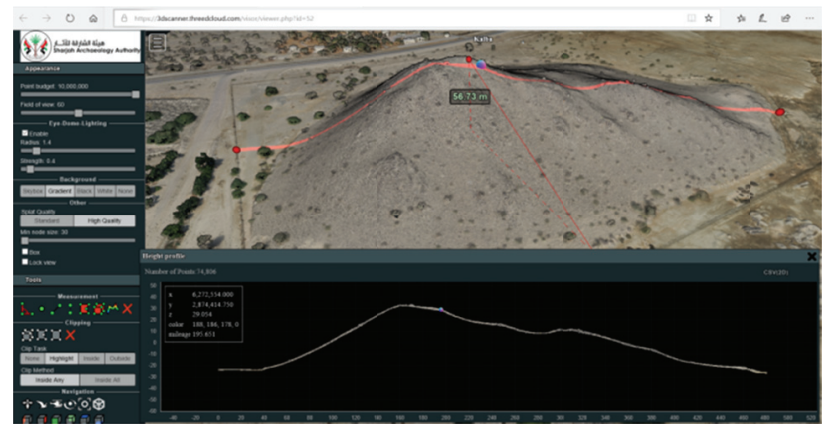

Figure 8. Point cloud of Khatm al Melaha (UAE) archaeological site visualized with Potree (free open-source WebGL), adaptation in the threeDcloud web platform. Large point clouds obtained by photogrammetry techniques with a professional eBee mapping drone (GSD $3.65 \mathrm{~cm} / \mathrm{px}$.)

- Web mapping GIS with the integration of the orthophoto and each of the blocks documented in different layer types (Figure 9). This enables analysing the different styles and morphologies of the rock art stone blocks throughout the entire recorded archaeological site.
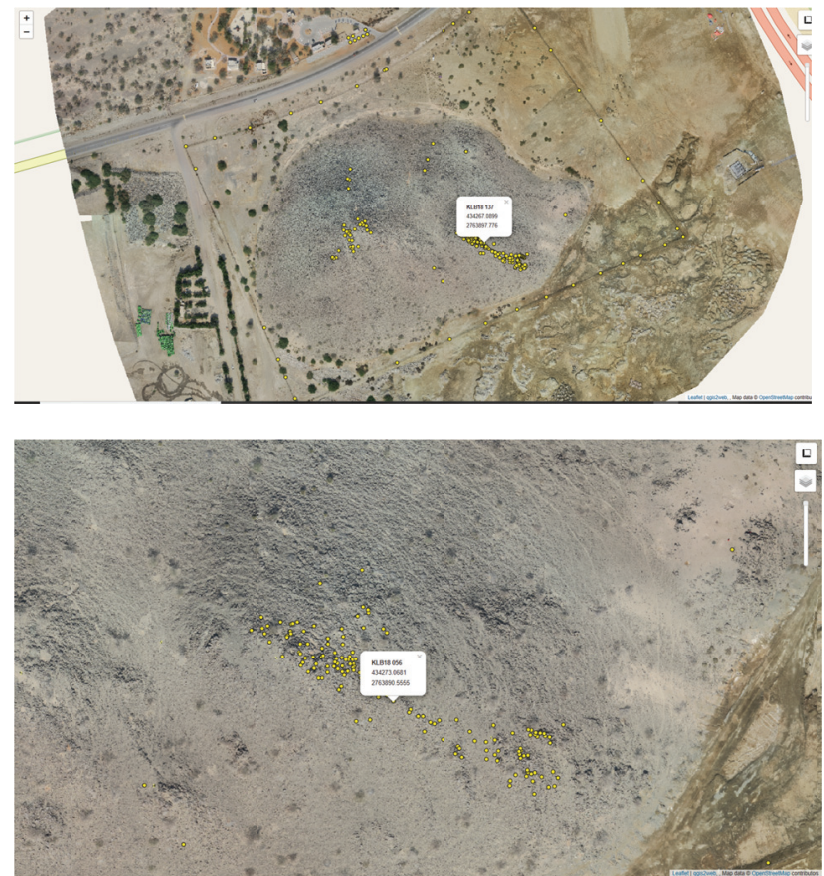

Figure 9. Location of each open rock art panel in the archaeological site with an orthophoto by tiles in a web mapping (EPSG:32640). Distribution, stylistic differentiation, and link to the remaining of the data recorded.

- 3D Mesh with the possibility of digital enhancement with the de-correlation view based on indirect system (vid. 4.1), DStretch and Meshlab (radiance scaling) (Figure 6). This is clearly an improvement in the view over some representations.

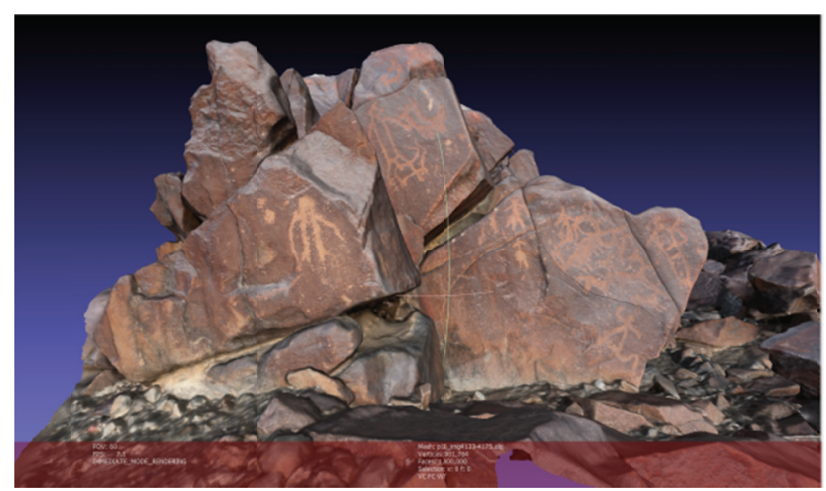




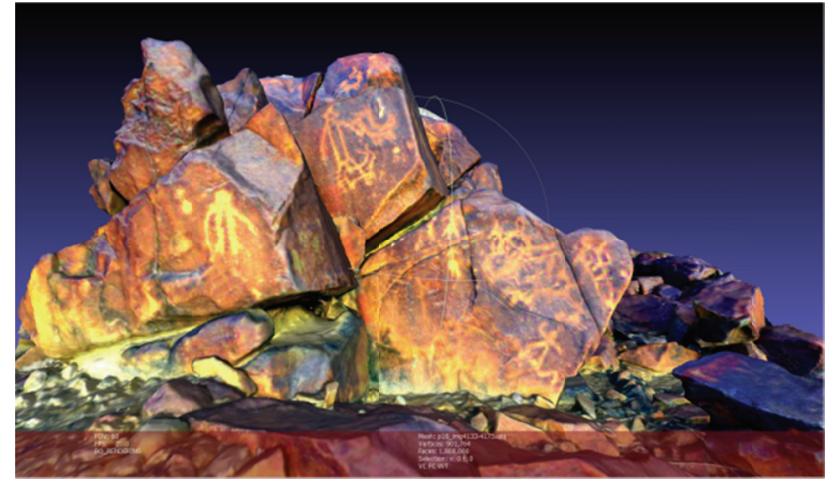

Figure 10. Rock art engraving sample of site number 34 in Khatm al Melaha (UAE). Conversion of the 3D model in the open-source MeshLab from OBJ mesh to JavaScript formats (JSON). 3D textured mesh from RGB (above) and 3D textured mesh from de-correlation view through DStretch plugin

(enhancement YDT, gen purpose, yellows) (below).

- 360-degree spherical views from different points of the hill, in order to improve the spatial understanding of the archaeological site from an immersive perspective.

\section{CONCLUSION}

Following on the preliminary phase of this research, in which we are integrating and analysing the data obtained in all three completed surveys, in this paper we propose the following. Firstly, we put forward an approximation to how to generate a $2 \mathrm{D}$ and $3 \mathrm{D}$ online repository data to study common stylistic patterns of engravings, dispersion models, and detailed analysis of each engraving through a common web page. Secondly, we propose a method that integrates interrelated models at different scales through a web platform (threeDcloud) without the need for additional software or plugins. Finally, we suggest that in combining these geomatics techniques will advance our efforts in preventive control, conservation and interpretation of the open-air rock art.

As conclusion, the success of a process in data recording openair rock art that standardises techniques lies in simplifying systems, which is a common goal of current research. For a process to be fully implemented, it must allow public management of geometric results, through technical, scientific and intellectual property consensus. Data should be easily accessible both graphically and metrically, moving towards selfmanagement and permitting the use of these tools in research. Democratisation of technology has repeatedly taken place over the last 150 years in photography, aviation, computing, and currently in the use of drone or RPAS with geometric and graphic aims, applying remote sensing techniques in the recording of unexcavated archaeological sites. Nowadays, the challenge lies in the use of all this varied data in a recording process useful for both scientific research and dissemination in the field of open-air rock art.

\section{FUTURE WORK}

This research has represented a preliminary study in Khatm Al Melaha, focusing in systematic prospection as well as in both metric and graphic documentation. It will be completed in the following years with new archaeological intervention campaigns. The aim is to yield common stylistic patterns that support the styles proposed from the prospection of other nearby access areas further inland. Once the digital 2D information repository and the remaining three-dimensional models have been completed, new studies relating all settlement patterns from the hill to their connection with the former coastline and the N-S communication route will be established.

\section{ACKNOWLEDGEMENTS}

Research campaigns have been carried out thanks to the collaboration of SHARJAH ARCHAEOLOGY AUTHORITY (Emirate of Sharjah, United Arab Emirates). This work was developed in the framework of the two R\&D\&I projects HAR2015-65649-C2-2-P S2015/HUM3377 (CAM/FEDER).

\section{REFERENCES}

Anati, E., 1968a. Rock Art in Central Arabia, Vol. 1. The 'Oval-Headed' People of Arabiat. Louvain, Bibliothèque du Muséon.

Anati, E., 1968b. Rock Art in Central Arabia, Vol. 2/1. FatTailed Sheep in Arabia. Louvain, Bibliothèque du Muséon.

Anati, E., 1968c. Rock Art in Central Arabia, Vol. 2/2. The 'Realistic-Dynamic' Style of Rock Art in the Jebel Qara. Louvain, Bibliothèque du Muséon.

Anati, E., 1972. Rock Art in Central Arabia, Vol. 3. Corpus of Rock Engravings. Pts. I-II. Sectors A-H, From Taif to Mahash Wells. Louvain, Bibliothèque du Muséon.

Anati, E., 1974. Rock Art in Central Arabia. Vol. 4. Corpus of Rock Engravings, Pt. III. Sectors J-Q, Qahra Range to Najran. Louvain, Bibliothèque du Muséon.

Bahn, P., 1997. Prehistoric Art. Cambridge Illustrated History. Cambridge.

Bea, M. and Angás, J., 2017. Geometric documentation and virtual restoration of the rock art removed in Aragón (Spain). Journal of Archaeological Science: Reports. 11, pp. 159-168.

Bednarik, R.G. and Khan, M., 2005. Scientific studies of Saudi Arabian Rock Art. Rock Art Research, 22(1), pp. 49-81.

Bednarik, R.G. and Khan, M., 2017. New rock art complex in Saudi Arabia. Rock Art Research, 34(2), pp. 179-188.

Boutsi, A.-M., Ioannidis, C. and Soile, S., 2019. Interactive online visualization of complex 3D geometries, Int. Arch. Photogramm. Remote Sens. Spatial Inf. Sci., XLII-2/W9, 2019, pp. 173-180, https://doi.org/10.5194/isprs-archives-XLII-2W9-173-2019

Carr, C. and Neitzel, J.E. (eds.)), 1995. Style, Society, and Person. Archaeological and Ethnological perspectives. Plenum Press, New York.

Carrero-Pazos, M., Vilas-Estévez, B. and Vázquez Martínez, A., 2018. Digital imaging techniques for recording and analysing prehistoric rock art panels in Galicia (NW Iberia). Digital Applications in Archaeology and Cultural Heritage. 8, pp. 35-45. https://doi.org/10.1016/j.daach.2017.11.003

Conkey, M. and Soffer, O. (eds.), 1997. Beyond Art. Pleistocene image and symbol. Memoirs of the California Academy of Sciences, 23. 
Defrasne, C., 2014. Digital image enhancement for recording rupestrian engravings: applications to an alpine rockshelter. Journal of Archaeological Science 50, pp. 31-38.

Domingo, I., 2014. Rock art recording methods: from traditional to digital. In: Smith, C. (ed.). Encyclopedio of Global Archaeology. Springer, pp. 6351-6357.

Hixon, S.W., Lipo, C. P., Hunt, T.L. and Lee, C., 2018. Using Structure from Motion mapping to record and analyze details of the Colossal Hats (Pukao) of monumental statues on Rapa Nui (Easter Island). Advances in Archaeological Practice, 6(1), pp. 42-57.

Jasim, S.A., Uerpmann, M. and Uerpmann, H.P., 2016. Mleiha: The Unwritten History, pp. 15-74.

Khan, M., 2007. Rock art of Saudi Arabia across twelve thousands years. Riyadh, Saudi Commission for Tourism and Antiquities.

Khan, M., 2013. Rock Art of Saudi Arabia. Arts, 2, pp. 447475. https://doi.org/10.3390/arts2040447

Le Quellec, J.L., Duquesnoy, F. and Defrasne, C., 2015. Digital

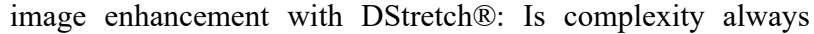
necessary for efficiency? Digital Applications in Archaeology and Cultural Heritage 2, pp. 55-67.

Le Quellec, J.L., Harman, J., Defrasne, C. and Duquesnoy, F., 2013. DStretch ${ }^{\circledR}$ et l'amélioration des images numériques: applications à l'archéologie des images rupestres. Les Cahiers de l'AARS 16, pp. 177-198.

Lorblanchet, M., 1993. Finalité du relevé. In: GRAPP. L'art parietal paleolithique. Techniques et methodes d'étude. Ministère de l'Enseignement Supérieur et de la Recherche. pp. 329-337.

Newton, L.S. and Zarins, J., 2000. Aspects of Bronze Age art of southern Arabia: The pictorical landscape and its relation to economic and socio-political status. Arabian Archaeology and Epigraphy, 11, pp. 154-179.

Otero, X., Farjas, M. and Santos, M., 2016. La historia en el paisaje: diferentes lugares y análogas representaciones. Análisis e interpretación con las nuevas tecnologías de modelización virtual. In: Proceedings of the 8th International Congress on Archaeology, Computer Graphics, Cultural Heritage and Innovation, ARQUEOLÓGICA 2.0, Universitat Politècnica de València, Valencia, pp. 321-323.

Otero, X., Farjas, M., Santos, M. and Angás, J., 2017. Diferentes paisajes y análogas representaciones. Interpretación arqueológica con tecnologías de ingeniería inversa. In: Primer Congreso en Ingeniería Geomática; Universitat Politècnica de València, Valencia, pp. 8-14.

Ovejero, M., 2016. Nuevas tecnologías de ingeniería inversa para el estudio de los petroglifos del yacimiento Khatm al Melaha. Trabajo Fin de Grado. Universidad Politécnica de Madrid. E.T.S.I. en Topografía, Geodesia y Cartografía.

Papadaki, A.I., Agrafiotis, P., Georgopoulos, A. and Prignitz, S., 2015. Accurate 3D scanning of damaged ancient greek inscriptions for revealing weathered letters. International
Archives of the Photogrammetry, Remote Sensing and Spatial Information Sciences, 5, W4.

https://doi.org/10.5194/isprsarchives-XL-5-W4-237-2015

Potree. Available online: http://potree.org/ (accessed on 2 May 2019).

Roe, P.G., 1995. Style, Society, Myth, and Structure. In: C. Carr and J.E. Neitzel (eds.), Style, Society, and Person. Archaeological and Ethnological perspectives. Plenum Press, New York, pp. 27-76.

Rogerio-Candelera, M.A., Jurado, V., Laiz, L. and SaizJiménez, C., 2011. Laboratory and in situ assays of digital image analysis based protocols for biodeteriorated rock and mural paintings recording. Journal of Archaeological Sciences 38 (10), pp. 2571-2578.

Sanz de Sautuola, M., 1880. Breves apuntes sobre algunos objetos prehistóricos de la provincial de Santander. Imp. y lit. de Telesforo Martínez. Santander.

Sapirstein, P., 2018. A high-precision photogrammetric recording system for small artifacts. Journal of Cultural Heritage, 31, pp. 33-45.

Sauvet, G., 2011. Prólogo. In: González-Pumariega Solís, M. 2011. La cueva de El Pindal 1911-21011. Estudio de su arte rupestre cien años después de «Les Cavernes cantabriques de la région cantabrique». Mensula Ediciones, pp. 13-15.

Schütz, M., 2016. Potree: Rendering Large Point Clouds in Web Browsers. Faculty of Informatics at the Vienna University of Technology.

threeDcloud. Available online: http:/www.threedcloud.com/ (accessed on 2 May 2019).

U.S. Geological Survey (USGS), Earth Resources Observation and Science (EROS) Center. Declassified images of the CORONA program. Available online: https://earthexplorer.usgs.gov (accessed on 2 May 2019).

Ziolkowski, M.C., 1998. A study of the petroglyphs from Wadi al-Hayl, Fujairah, United Arab Emirates (1). Arabian Archaeology and Epigraphy, 9, pp. 13-89.

Ziolkowski, M.C., 2007. Rock on art: petroglyph sites in the United Arab Emirates. Arabian Archaeology and Epigraphy, 18, pp. 208-238.

Ziolkowski, M.C. and Hassan, S.A.M., 2000. Three petroglyphs from the Emirate of Fujairah, United Arab Emirates. Proceedings of the Seminar for Arabian Studies, 30, pp. 257-265. 